\title{
PRODUCT QUALITY DEVELOPMENT ANALYSIS OF RICE BRAN CAKE BASED ON CONSUMERS' EXPECTATION
}

\author{
Silvana Maulidah ${ }^{1 *}$, Heru Santoso Hadi Subagyo ${ }^{1}$, Sri Ratna Triyasari ${ }^{1}$ \\ ${ }^{1}$ Faculty of Agriculture, University of Brawijaya, Malang, East Java, Indonesia \\ *corresponding author : silvana.maulidah@yahoo.com
}

\begin{abstract}
This research analyzes consumer expectations for developing product quality of Rice Bran Cake. Quality Function Deployment (QFD) method is employed to ensure the product that entering the production phase will actually able to satisfy the consumer expectations. There are four phases in QFD method, namely; house of quality, parts deployment, process deployment, and production planning. The results coming from applying the four phases of QFD are: consumers require the quality development of Rice Bran Cake and considered price improvement, the addition of flavor, color, aroma, texture, shape, packaging, legality, durability, and net weight. Company's response to meet the consumer demand towards Rice Bran Cake that produced in the first phase is the addition of flavors, qualified ingredients, making innovative shapes, price adjustment, the addition of weight and size, packaging design, and no chemical preservatives. In the second phase of part deployment, the priorities which should be improved are natural ingredients usage, procurement of qualified ingredients, the addition of halal label, interested flavor, adjustments with other attributes, and the larger cake pan. The quality development designs of Rice Bran Cake that is produced in accordance with the order of weight values of the highest process planning are supply of raw materials, supply of additional materials, the addition of the appropriate flavors, the addition of food coloring, and packaging. Furthermore, the matrix production planning obtained according to the results of importance weight are making various flavors, the supply of qualified ingredients, legality standardization, designing the forms of packaging, hygiene of tools and materials, and accuracy of production equipment.
\end{abstract}

Keywords: rice bran cake, consumer expectations, quality function deployment

\section{INTRODUCTION}

Indonesian agricultural sector is closely related to the industrial sector because the surplus from agriculture is used to buy products from industry and the industries need agriculture to provide food and to provide inputs for industries as well. Moreover, agriculture products also provide raw ingredients for the next processing and embedding added value in the processed products. The processed products commonly are produced by industries. The concern on food safety for healthy life can be a great opportunity for industries to exploit the market and bring new food products as expected consumers.

Rice bran is one of the side product of paddy milling process. Indonesia has abundant amount of rice bran; however, the utilization of that for human need is still limited in Indonesia. Therefore, rice bran can be employed as an innovation product in the food industry. The expectation is that food industry should continue to improve the quality of the products in order to meet the consumers' expectation.

Rice Bran Cake is a processed product by Small and Medium Enterprises (SME) of Bu Noer Aneka Rasa Malang, East Java, Indonesia, which is a new product in the food market that still needs product improvement.

This research uses Quality Function Deployment (QFD) method for acquiring the consumer expectation or preference of the product development. QFD method is developed to ensure that products which entering the production phase will actually able to satisfy the consumer expectations (Fandy and Diana, 2001). The method used in this research has four phases, which are house of quality, part deployment, process 
deployment, and production planning (Cohen, 1995).

The objectives of this research are to analyze consumer expectations of Rice Bran Cake in order to develop the quality of the product; to analyze the response of company to meet the consumer expectations on quality of Rice Bran Cake; and to identify the design of quality development of Rice Bran Cake.

\section{RESEARCH METHODS}

This research is located in Small and Medium Enterprises (SME) of $\mathrm{Bu}$ Noer Aneka Rasa Malang, East Java, Indonesia by purposive sampling. There are two type of respondents, which are the company and the consumers. The method to determine the respondents of consumers is non-probability sampling method of convenience sampling, and the number of samples used are 30 respondents.

Primary data are obtained from questionnaire, interview to the consumers and the company and documentation of collecting data. Secondary data are obtained generally in the form of structured notes or reports published in the archive from various agencies such as Statistics Indonesia, previous studies, and data of Small and Medium Enterprises (SME) of $\mathrm{Bu}$ Noer Aneka Rasa Malang.

Qualitative analysis in this research uses Quality Function Deployment (QFD) method, which has four phases, namely house of quality, parts deployment, process deployment, and production planning.

\section{RESULTS AND DISCUSSION}

The results from QFD are as follow.

\section{Phase 1: House of Quality (HOQ)}

Problem formulation regarding the expectations of consumers in order to develop the quality of Rice Cake Bran uses the first phase of QFD namely House of Quality (HOQ). The results of HOQ are some important mentioned below.

Some attributes of consumer expectations with response techniques have a strong relationship, moderate relationship, weak relationship, and no relationship. Examples of the strong relationship that occurs is the relationship between consumer expectations of taste with qualified ingredients technique response. Better quality of ingradients will affect the flavor of the product. Therefore, the taste and qualified ingredients have a strong relationship.

A moderate relationship is consumer expectations against the shape of product with the response techniques of price adjustment. Moreover, the weak relationship is the relationship between consumer expectations against durability with response techniques of packaging design.

Between the expectations of consumers and the response techniques that do not have the relationship is between aroma with the addition of weights and measures of the product. Taste, color, qualified ingredients, and no chemical preservative affect aroma of products. While the addition of the weight and size is influenced by the cleanness, packaging, price, shape, and texture. Then, between consumer expectations toward aroma with response techniques of weight gain and measures do not have a relationship.

\section{The company's response and consumer expectations}

The relationship between the responses of techniques and consumer expectations can be either strong positive relationship, positive, negative, strong negative, and have no relationship at all. Correlation analysis techniques aims to find out more about the conflicts that may occur and where possible take the most optimum conditions to produce products with the desired characteristics to the consumers.

The result shows that the strong positive among technical responses and the consumer expectation is the addition of the legality of the product with no relationships to the chemical preservatives. While the weak positive between technical responses and consumer expectation is the price adjustments and no chemical preservatives. In addition, the relationship between the responses that have a strong negative relationship is between packaging design and the addition of weights and size. The weak negative relationship relationship is the relationship between creating an innovative form and the addition of weights and size.

Response technique that must first be considered and improved is the quality of raw materials. Raw materials must meet the quality needed, so the product made is going to have the quality expected. Furthermore, to be considered and improved response both techniques is the addition of flavors. The variety of flavors provided by the company are preferred to consumers because 
those will give benefit to the consumers choosing what the preferred product chosen the most is. The third response techniques that must be considered and upgraded is more durable without chemical preservatives. Durability of safe products without chemical preservatives is very important. Furthermore, the fourth and fifth responses techniques that need to be considered and improved are the price adjustment and making an innovative form, size, and weight gain. The sixth response techniques to be improved is the design of the packaging and legality. Company needs to pay attention to those technique responses, because those will increase the preference and the consumer satisfaction. For more information is provided in Figure 1.

\section{Phase 2: Part Deployment}

Matrix of deployment part in Figure 2 describes critical design to the development of the product. Selecting the best design to meet the target, identify the parts and critical components, held research and development. On the part deployment matrix, the known value of the priority that must be considered first by the company is the use of natural materials with a value of 4.23. Essential natural ingredients to be added to the raw materials, such as the use of natural sweeteners, natural preservatives, natural appropriate flavors, and food coloring are safe to consume.

The second priority that needs to be considered by the company is the provision of qualified ingredients. Furthermore, the third priority is adding halal label that the product will be good and safe to consume. The fourth priority is to add flavors. The consumers want the pandan flavor that is preferred for Indonesian. The fifth priority is compliance with other attributes. The point is between one another attribute must be aligned and have a strong relationship. The sixth priority is to design and the larger cake pan. Unique and interesting shapes will increase consumer interest in consuming Rice Bran Cake. Larger pan of the cake will add to the size and weight of the cake, so that attributes with each other have a strong relationship. For part of deployment matrix is provided in Figure 2.

\section{Phase 3: Process Deployment}

Figure 3 is the result of process deployment matrix. In the column critical part elected has obtained part of the requirements identified in the part deployment matrix. At this critical part will be connected to the plans that have a relationship to be strong, moderate, weak, or even no relationship between the two.

The first priority is the provision of ingredients and the provision of additional materials. The company should continue to maintain the availability and quality of ingredients and additional material. The second priority that should be considered by company is additional flavor with appropriate taste. Addition flavor must be considered as well is the food safety, namely the need to use natural flavor without chemical preservatives. The third priority is the addition of food coloring, using food coloring materials that is safe, so it will maintain consumer health and attractiveness of the product as well for consuming Rice Bran Cake. The fourth priority is the packaging. It is worth for protecting the product from direct contact with outdoor air and can also be used as an enticement to attract consumers.

After determining the relationship between the planning processes with a critical part elected, the next step before going inside the production planning matrix is to determine the critical process, which can later be analyzed in the fourth house. Determination of critical processes can be seen in Figure 3, which is determined from the value of the priority process deployment matrix.

\section{Phase 4: Production Planning}

Production planning matrix resulted in a proposed action to the company in an effort to improve the quality of its products. There are six proposed of improvement actions generated in the production planning matrix. This planning can be used as a reference for the company to begin the process in improving quality of the product. This planning is a follow-up of selected predetermined processes.

The first priority performed by the company is making various flavors. Company must be able to be creative in creating a variety of flavors Rice Bran Cake. The second priority is the supply of quality ingredients. The third priority is standardization of legality. Note that there is no legality on the product Rice Bran Cake. The fourth priority is to redesign the packaging. Packaging that already exist on the Rice Bran Cake still cannot meet consumer expectations. Packaging design company should be better, as the customer wants is thick cardboard material and there is a section which is derived from a transparent plastic, so that the product seen by the consumer. Packaging using embossed design and bright color 
applications. The fifth is the cleanliness of the tools and materials. Company must pay attention to the cleanliness of the tools and materials to used, so that the healthiness of product remains guaranteed. The last production plan (sixth) is the precision of the means of production. Production processes using appropriate technology will facilitate the production process efficiently. 


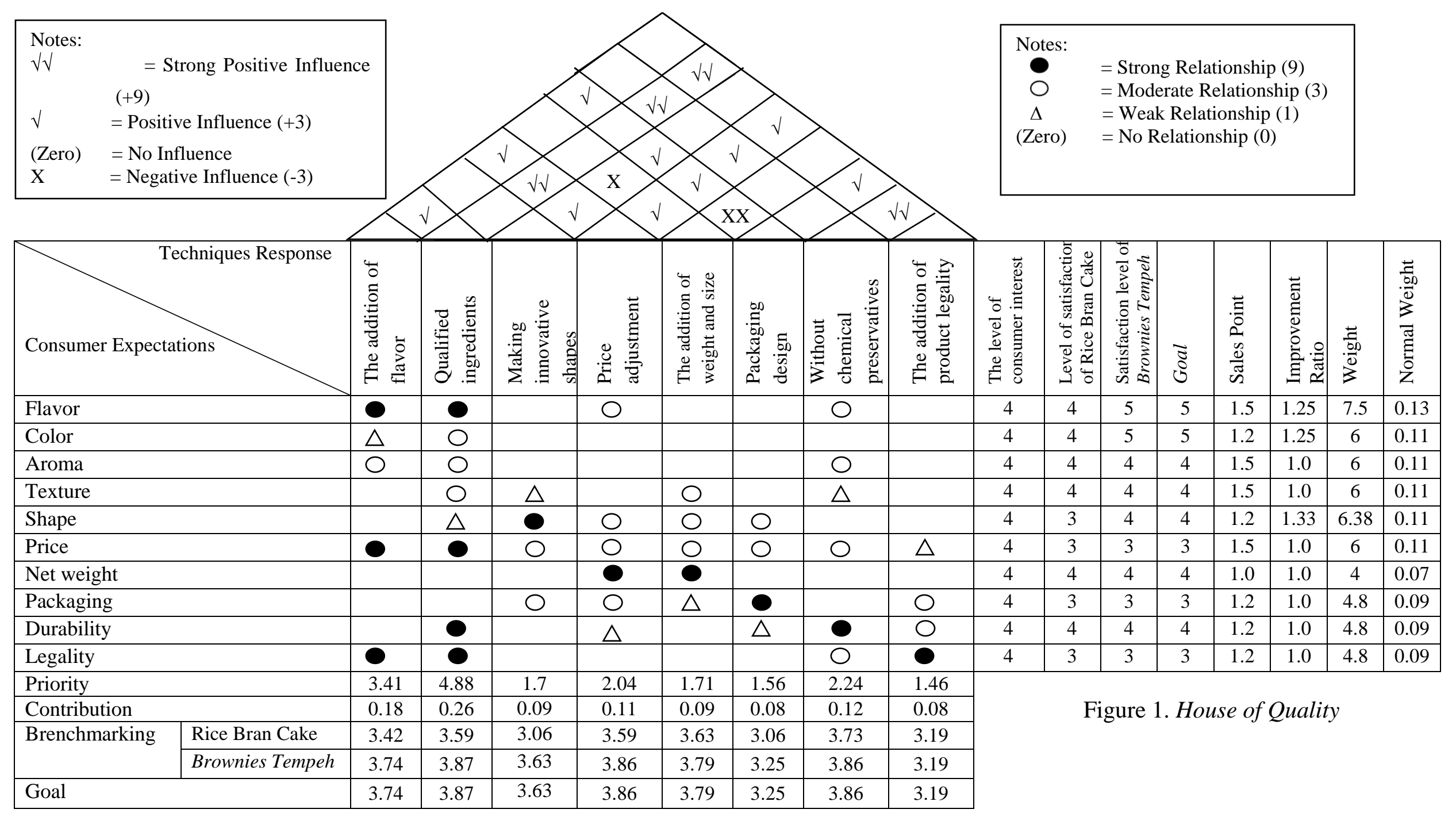


Part Requirements

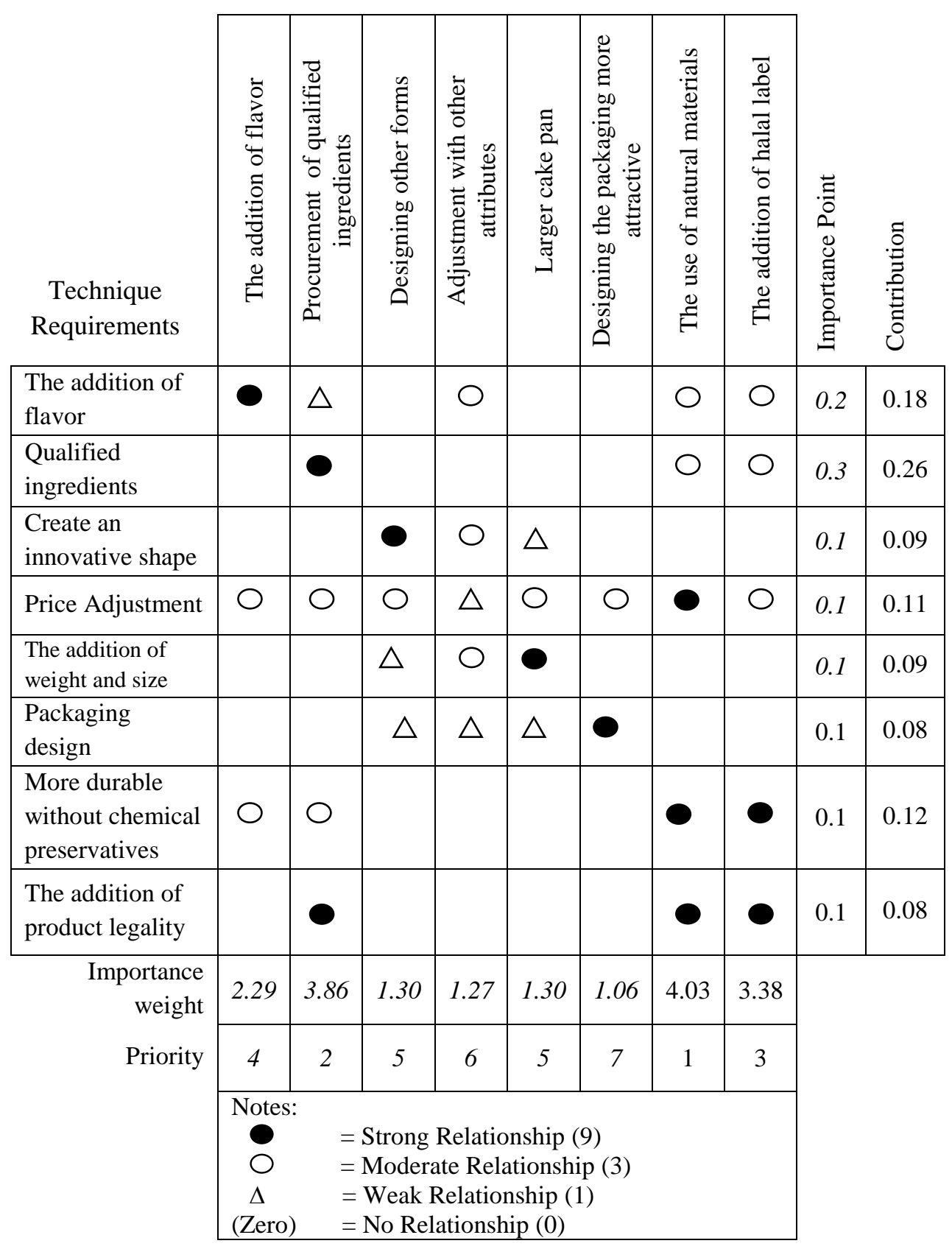

Figure 2. Part Deployment Matrix 


\begin{tabular}{|c|c|c|c|c|c|c|c|}
\hline Priority & Importance Weight & $\begin{array}{c}\text { Adjustment } \\
\text { with other } \\
\text { attributes } \\
\end{array}$ & $\begin{array}{c}\text { The } \\
\text { addition of } \\
\text { flavor }\end{array}$ & $\begin{array}{l}\text { The addition } \\
\text { of halal label }\end{array}$ & $\begin{array}{l}\text { Qualified } \\
\text { ingredients }\end{array}$ & $\begin{array}{c}\text { The use of } \\
\text { natural } \\
\text { materials }\end{array}$ & Plan Process \\
\hline 1 & 5.5 & & & $\bigcirc$ & O & 0 & Provision of raw materials \\
\hline 1 & 5.5 & & & $\mathrm{O}$ & O & 0 & Provision of additional material \\
\hline 9 & 0.2 & & & $\triangle$ & & & Provision of production equipment \\
\hline 11 & 0 & & & & & & Filtration / sifting rice bran \\
\hline 11 & 0 & & & & & & Measure the ingredients \\
\hline 11 & 0 & & & & & & Mixing \\
\hline 5 & 1.7 & & & $\bigcirc$ & $\bigcirc$ & $\triangle$ & Whisk the butter and sugar \\
\hline 7 & 0,8 & & & & O & & Adding the eggs \\
\hline 6 & 1.1 & & & & O & $\triangle$ & Adding the dry ingredients \\
\hline 11 & 0,0 & & & & & & Stirring \\
\hline 2 & 5.3 & O & O & O & O & O & Add the essen according to taste \\
\hline 3 & 2.8 & $\triangle$ & $\bigcirc$ & $\mathrm{O}$ & O & $\bigcirc$ & Add food coloring \\
\hline 11 & 0 & & & & & & Whisk until evenly \\
\hline 11 & 0 & & & & & & Preheat oven \\
\hline 8 & 0.3 & 0 & & & & & Put the dough into the pan \\
\hline 11 & 0 & & & & & & Put it in the oven \\
\hline 11 & 0 & & & & & & Serving the cake \\
\hline 4 & 2.3 & O & & O & & & Packaging \\
\hline 11 & 0 & & & & & & Sales \\
\hline \multirow{3}{*}{\multicolumn{2}{|c|}{$\begin{array}{ll}\text { Notes: } \\
\\
(9)=\text { Strong Relationship } \\
\text { (3) = Moderate } \\
\text { Relationship } \\
\Delta & (1)=\text { Weak Relationship }\end{array}$}} & 0.1 & 0.2 & 0.2 & 0.3 & 0.3 & \multirow{3}{*}{$\begin{array}{l}\text { Importance Point } \\
\text { Relative Weight } \\
\text { Importance weights from selected parts } \\
\text { requirements }\end{array}$} \\
\hline & & 0.09 & 0.15 & 0.23 & 0.26 & 0.27 & \\
\hline & & 1.27 & 2.29 & 3.38 & 3.86 & 4.03 & \\
\hline
\end{tabular}

Figure 3. Process Deployment 


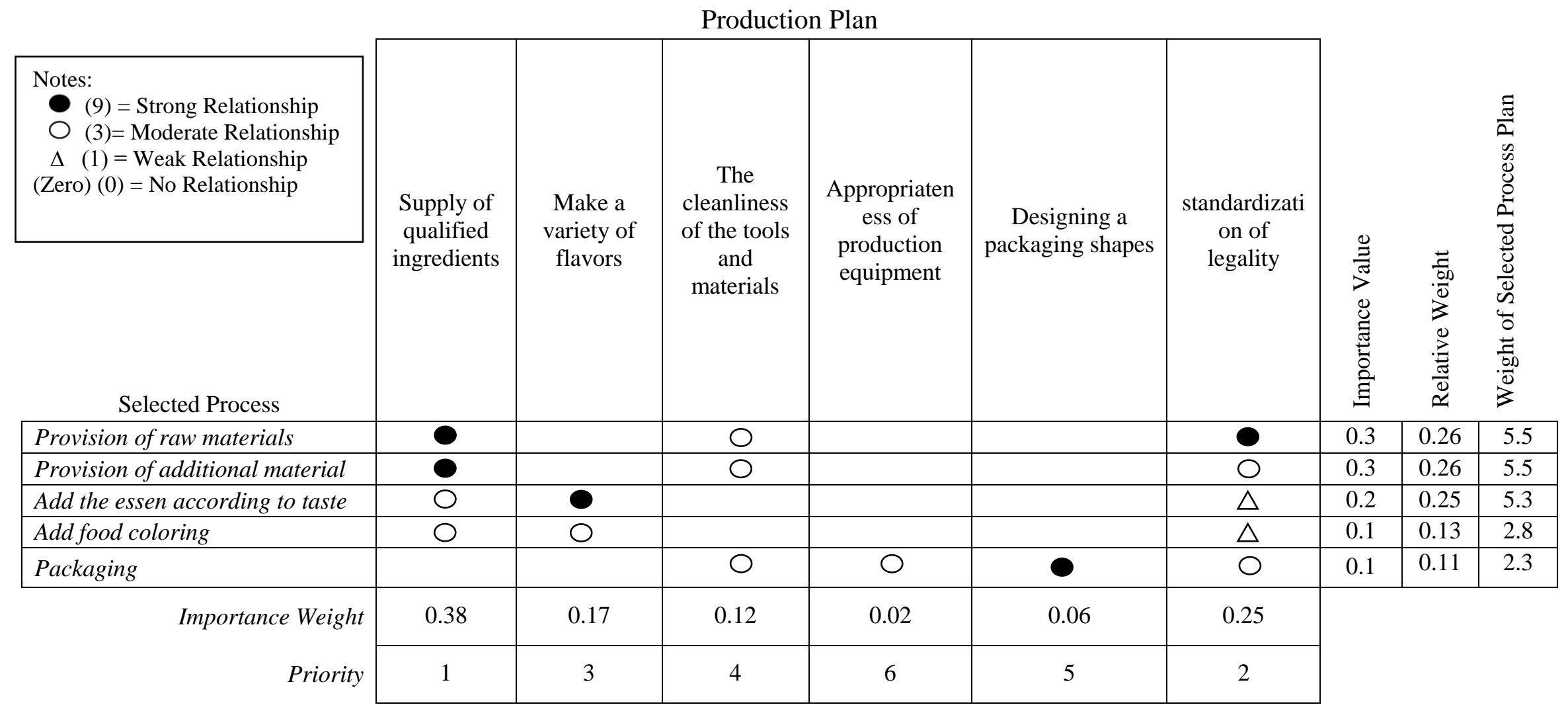

Figure 4. Production Planning Matrix 


\section{CONCLUSION}

The company of rice band cake should consider carefully some important points. They are:

1. Improve consumer needs of normal weight values, the first is the price (0.13), the second is the flavor (0.12), the third with a value of 0.10 is the color, aroma, texture, shape, packaging, and legality. The fourth is the durability (0.08), and the fifth is net weight (0.07).

2. The other company response in meeting consumer demand for rice bran cake are the quality of ingredients (4.88), the addition of variance (3.41), without the chemical preservatives (2.24), the price adjustment (2.04), create innovative shapes and sizes and weight gain (1.7), packaging design (1.56), the addition of the legality of the product (1.46). In the second phase of the part deployment priority that should be addressed and corrected is the use of natural materials (4.03), procurement of quality raw materials (3.86), the addition of halal label (3.38), add flavors (2.29), larger prints (1.30), adjustment with other attributes (1.27), and designing packaging more attractive (1.06).

3. The product designs for increasing quality of the product are the provision of raw materials and additives (5.5), add the appropriate flavor essence (5.3), additional essence used to be in accordance with the flavor to be produced; add food coloring (2.8); packaging (2.3). Furthermore, the production planning matrix obtained in accordance sequence of first importance weight is the result of supply of quality material (0.38), standardization of legality $(0.25)$, a variety of flavors (0.17), the cleanliness of the tools and materials (0.12), designing form of packaging ( 0.06 the accuracy of production equipment $(0.02)$.

\section{REFERENCES}

Benner, M., Linnemann, A.R., Jongen, W.M.F., Polstar, P. 2001. Quality Function Deployment (QFD)-Can It Be Used To Develop Food Product. Jurnal. Department of Agrotechnology. Wageningen University. Wageningen

Cohen, Lau. 1995. How to Make QFD Work for You. Engineering Process Improvement
Series. Addison Wesley Publishing Company

Dale. 1994. Total Quality Management. Third Edition, Pearson, New. Jersey

Djati. 2003. Simulation, Theory and Applications. Penerbit Andi. Yogyakarta

Hadipranata. 1997. Consumer Behaviour: 6th Edition. Translated by F.X. Budiyanto. Binarupa Aksara. Jakarta

Kotler, Philip dan Armstrong, 2002. Principles of Marketing: Second Edition. Prentice Hall.

Guba dan Lincoln. 1985. Effective Evaluation. Jossey Bass Publisher. San Fransisco

Santosa. 1992. Customer Loyalty in the Hotel Industry, the Role of Customer Satisfaction and Image. International Journal of Contemporary Hospitality Management. Volume 1216,p.349

Soekartawi, 1993. Basic Principles of Agricultural Economics. Theory and Applications: Revised Edition. PT Raja Grafindo Persada. Jakarta

Tjiptono, Fandy and Anastasia Diana. 2001. Total Quality Management. Penerbit Andi. Yogyakarta 